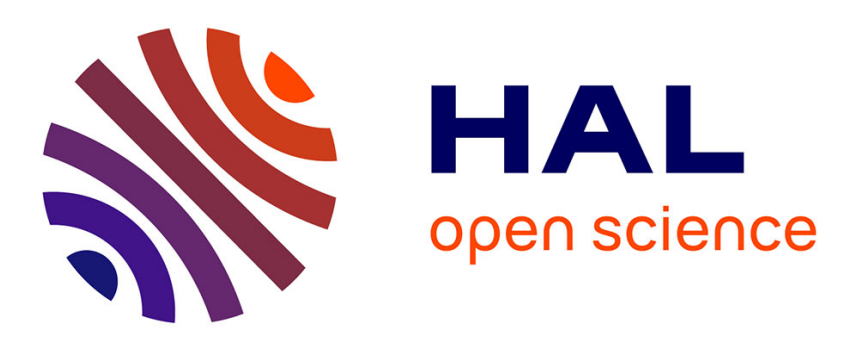

\title{
TSPO2 translocates 5-aminolevulinic acid into human erythroleukemia cells
}

Hana Manceau, Sophie Lefevre, Arienne Mirmiran, Claude Hattab, Hugo R Sugier, Caroline Schmitt, Katell Peoc'H, Herve Puy, Mariano A. Ostuni, Laurent Gouya, et al.

\section{To cite this version:}

Hana Manceau, Sophie Lefevre, Arienne Mirmiran, Claude Hattab, Hugo R Sugier, et al.. TSPO2 translocates 5-aminolevulinic acid into human erythroleukemia cells. Biology of the Cell, In press, 10.1111/boc.201900098 . hal-02490892

\section{HAL Id: hal-02490892 https://hal.science/hal-02490892}

Submitted on 25 Feb 2020

HAL is a multi-disciplinary open access archive for the deposit and dissemination of scientific research documents, whether they are published or not. The documents may come from teaching and research institutions in France or abroad, or from public or private research centers.
L'archive ouverte pluridisciplinaire HAL, est destinée au dépôt et à la diffusion de documents scientifiques de niveau recherche, publiés ou non, émanant des établissements d'enseignement et de recherche français ou étrangers, des laboratoires publics ou privés. 
TSPO2 translocates 5-aminolevulinic acid into human erythroleukemia cells

\section{Authors}

Hana MANCEAU ${ }^{1,2}$, Sophie D LEFEVRE ${ }^{3,4}$, Arienne MIRMIRAN ${ }^{1}$, Claude HATTAB ${ }^{3,4}$, Hugo R SUGIER ${ }^{3,4}$, Caroline SCHMITT ${ }^{1,5}$, Katell PEOC'H ${ }^{1,2}$, Hervé PUY ${ }^{1,5}$, Mariano A OSTUNI $^{3,4}$, Laurent GOUYA ${ }^{1,5}$, Jean-Jacques LACAPERE ${ }^{6}$

\section{Affiliations}

${ }^{1}$ Université de Paris, Centre de recherche sur l'inflammation, INSERM U1149, F-75018 Paris, France

${ }^{2}$ Laboratoire de Biochimie, Hôpital Beaujon, Assistance Publique-Hôpitaux de Paris, DHU Unity, 92110 Clichy, France

${ }^{3}$ Université de Paris, UMR_S1134, Integrated Biology of Red Blood Cell, INSERM F-75015, Paris, France

${ }^{4}$ Institut National de Transfusion Sanguine, F-75015, Paris, France

5 Centre Français des Porphyries, Hôpital Louis Mourier, Assistance Publique-Hôpitaux de Paris, 92701 Colombes, France

${ }^{6}$ Sorbonne Université, Ecole Normale Supérieure, PSL University, CNRS, Laboratoire des Biomolécules (LBM), F-75005 Paris, France

Running Title: TSPO2 as an ALA transporter 


\section{Abstract (250 words)}

Background: 5-aminolevulinic acid (ALA) is the first precursor of heme biosynthesis pathway. The exogenous addition of ALA to cells leads to protoporphyrin IX (PPIX) accumulation that has been exploited in photodynamic diagnostic and photodynamic therapy. Several types of ALA transporters have been described depending on the cell type, but there was no clear entry pathway for erythroid cells. The $18 \mathrm{kDa}$ translocator protein (TSPO) has been proposed to be involved in the transport of porphyrins and heme analogs.

Results: ALA-induced PPIX accumulation in erythroleukemia cells (UT-7, K562) was impaired by PK 11195, a competitive inhibitor of both transmembrane proteins TSPO (1 and 2). PK 11195 did not modify the activity of the enzymes of heme biosynthesis, suggesting that ALA entry at the plasma membrane was the limiting factor. In contrast, porphobilinogen (PBG)-induced PPIX accumulation was not affected by PK 11195, suggesting that plasma membrane TSPO2 is a selective transporter of ALA. Overexpression of TSPO2 at the plasma membrane of erythroleukemia cells increased ALA-induced PPIX accumulation, confirming the role of TSPO2 in the import of ALA into the cells.

Conclusions: ALA-induced PPIX accumulation in erythroid cells involves TSPO2 as a selective translocator through the plasma membrane.

Significance: This is the first characterization of molecular mechanisms involving a new actor in ALA transport in ALA-induced PPIX accumulation in erythroleukemia cells, which could be inhibited by specific drug ligands. 


\section{Abbreviations:}

ALA, 5-aminolevulinic acid; ALAS: 5-aminolevulinic acid synthase; ALAD: 5aminolevulinic acid dehydratase; COPRO: coproporphyrinogen; CPOX: coproporphyrinogen oxidase; EGFP: enhanced green fluorescent protein; EPO: erythropoietin, FECH: ferrochelatase; GABA: $\gamma$-aminobutyric acid; GPA: glycophorin A; HMBS: hydroxymethylbilane synthase; PBG: porphobilinogen; PK 11195: N-butan-2-yl-1-(2chlorophenyl)-N-methylisoquinoline-3-carboxamide; PPIX: protoporphyrin IX; PPOX: protoporphyrinogen oxidase; UROD: uroporphyrinogen decarboxylase; UROS: uroporphyrinogen synthase; TSPO: $18 \mathrm{kDa}$ translocator protein 


\section{$\underline{\text { Introduction }}$}

5-aminolevulinic acid (ALA) is an endogenous amino acid, the first precursor of porphyrin biosynthesis in eukaryotic and prokaryotic cells. In mammals, ALA is synthesized in the mitochondria by the ALA-synthase enzyme (ALAS) from the amino acid glycine and the anaplerotic compound of the Krebs cycle succinyl CoA. Conjugation of eight ALA molecules yields protoporphyrin IX (PPIX) in the cytosol and finally leads to the formation of heme by insertion of iron, thanks to the activity of the mitochondrial rate-limiting enzyme ferrochelatase (Supplementary Figure S1).

PPIX is a photoactive molecule used for therapeutic purposes. Exogenous ALA is administered topically or systemically and penetrates into all cells, in which it is metabolized to generate high concentrations of PPIX. The bioactivation of ALA uses the enzymes of the heme biosynthesis pathway, and that can be exploited in photodynamic diagnosis (PDD) and photodynamic therapy (PDT) (Ishizuka et al., 2011). Exogenous administration of ALA bypasses the natural regulation exerted by heme or iron on ALA synthesis. A functional bottle neck on the heme synthesis is observed in the ferrochelatase activity, which is too low to convert excess of PPIX to heme, resulting in the accumulation of PPIX within cells. In PDT several hours after the administration of ALA, when PPIX has been synthesized, cancer cells are exposed to light, which leads to the excitation of the PPIX-photosensitizer and formation of radicals and reactive oxygen species that exerts cellular toxicity (Ishizuka et al., 2011).

ALA-mediated PPIX biosynthesis has many other advantages. PPIX is a basically monomeric compound with a high fluorescence yield and photosensitizing capacity due to its good singlet oxygen quantum efficiency that is rapidly metabolized in vivo (Ishikawa et al., 2011). ALA is a polar molecule and at physiological $\mathrm{pH}$ occurs mainly as a charged zwitterion, which accounts for its low lipid solubility and reduced bioavailability. The elucidation of the 
molecular mechanism of ALA entrance in tumor cells will improve the clinical use of ALA in PDT.

Moreover, ALA is a pivotal actor for induction of erythroid differentiation in vitro (Malik et al., 1988). Exogenous ALA bypasses the rate limiting enzyme ALA synthase, and accelerates heme synthesis. ALA-induced erythroid differentiation of human myelogenous leukemia K562 (Fujiwara et al., 2014) and murine erythroleukemia MEL cells, leading to cell hemoglobinization (Malik et al., 1988).

It has been reported that ALA uptake was mediated by different transporters depending on the cell type. In Saccharomyces cerevisiae, it was first observed that ALA was transported by a transport system (Bermudez Moretti et al., 1995), later characterized as the $\gamma$-aminobutyric acid (GABA) permease Uga4 (Bermudez Moretti et al., 1996). In human cell lines, a similar competition between ALA and GABA was observed, through amino acids carrier systems through the plasma membrane (Rud et al., 2000). In Escherichia coli, the uptake of ALA was mediated by an amino acid transporter, the dipeptide permease (Verkamp et al., 1993). When administrated in vivo to yeast and ovocytes, ALA used intestinal and renal apical peptide transporters (PEPT) for entering epithelial cells (Doring et al., 1998). PEPT1 and PEPT2 were demonstrated to be selective of ALA versus GABA and to be electrogenic as a consequence of $\mathrm{H}^{+}$/ALA cotransport (Doring et al., 1998). The human homologues peptide transporter (hPEPT1 also called SLC15A1 for solute carrier family 15 member 1) and proton-coupled amino acid transporter (hPAT1 also called SCL36A1) were shown to mediate ALA absorption in Caco-2 cells (Frolund et al., 2010). Recently, it was showed that PEPT2 variants with reduced affinity for ALA impacted the severity and prognosis of Porphyria-Associated Kidney Disease (PAKD) in French Caucasian individuals by altering the renal tubular ALA reabsorption (Tchernitchko et al., 2016). Variants in the gene encoding PEPT2 were associated with a reduced severity and a slower progression of PAKD. 
However, the entry of ALA into erythroid cells is not yet elucidated. Different cell models are available to study ALA induced erythroid differentiation. (i) K562 which present characteristics of early erythroid differentiation states (Fujiwara et al., 2014). (ii) EPOdependent UT-7 cells that display erythroid properties characteristic of more advanced erythroid differentiation states (Komatsu et al., 1993). Both could be used to analyze the regulation of hemoglobin synthesis (McHale et al., 1999).

The $18 \mathrm{kDa}$ translocator protein (TSPO), previously known as peripheral benzodiazepine receptor (PBR, Papadopoulos et al., 2006), has been proposed to be involved in the transport of porphyrins and heme analogs (Taketani et al., 1994; 1995). TSPO is expressed both at the plasma and outer mitochondrial membranes (Papadopoulos et al., 2006). Recent data show that isoform 2 of TSPO (TSPO2) is present in the plasma membrane of mature red blood cells (RBC) and expressed on erythroid cells in late differentiation states (Fan et al., 2009; An et al., 2014; Margenidas-Freixa et al., 2016)

The aim of this study was, therefore, to determine the role played by TSPO in ALA incorporation in human erythroleukemia cells. Our results showed that TSPO2 is expressed at the plasma membrane of erythroid cells and that ALA mediated PPIX accumulation was impaired by PK 11195, as a competitive TSPO specific ligand. Amino acids were not a competitor of ALA mediated PPIX accumulation, contrary to GABA. TSPO2 over-expression at the plasma membrane significantly increased ALA induced PPIX accumulation within erythroleukemia cells.

\section{$\underline{\text { Results }}$}

\section{ALA-mediated PPIX accumulation in erythroleukemia cell lines}

It has been previously shown that exogenous ALA enters to K562 cells and is rapidly metabolized in PPIX and heme (Fujiwara et al., 2014). 
Upon ALA supplementation of the culture medium, K562 cells accumulated intracellular porphyrin in time and dose-dependent manner (Figure 1A and 1B), as measured by flow cytometry. According to the cell viability (MTT assay), the used ALA concentrations were not toxic to the K562 cells. At a low concentration (below $0.2 \mathrm{mM}$ ), almost no PPIX could be detected in the cells, suggesting the involvement of a transporter for ALA since the concentration gradient should be sufficient to enter the cells. At a concentration above $0.2 \mathrm{mM}$, the PPIX accumulation showed a linear concentration-dependency up to $1 \mathrm{mM}$. In the presence of the high affinity ligand for TSPO, the PK 11195, ALA-induced PPIX accumulation was significantly reduced (Figure 1C). PPIX accumulated only in the cells (Figure 1D), whereas coproporphyrin and uroporphyrin were also secreted. Moreover, PK 11195 reduced the amount of coproporphyrin but not the PPIX (Figure 1E). We performed western blots of K562 cell lysate to characterize TSPO2 (Figure 1F) that was previously described to be localized in red blood cells plasma membrane and erythroid cells (Fan et al., 2009; An et al., 2014; Margenidas-Freixa et al., 2016). TSPO2 has a molecular weight about19 $\mathrm{kDa}$ and was mostly observed as a trimer (above standard of $55 \mathrm{kDa}$ ). To confirm the role of TSPO2 in ALA transport in erythroid cells, we studied it in another erythroid cell line, the UT-7 (Figure 1F).

We first confirmed, using immunohistochemical studies, the presence of TSPO2 at the plasma membrane of UT-7 cells (Figure 2A). Single perinuclear punctuate structure might be TSPO2 in the Golgi undergoing to the plasma membrane. Western blots of subcellular fractions support that TSPO2 was mostly localized at the plasma membrane (Figure 2B), as a mixture of different oligomers (monomer $19 \mathrm{kDa}$, dimer $38 \mathrm{kDa}$, trimer $57 \mathrm{kDa}$, and tetramer $76 \mathrm{kDa}$ ). Upon ALA treatment the UT-7 cells accumulated higher concentrations of porphyrins compared to those observed in K562 cells (almost four times; Figure 3A). The same biphasic ALA concentration dependency of PPIX accumulation was observed for K562 and UT-7 with 
no PPIX accumulation below $0.2 \mathrm{mM}$ and a linear dependence above $0.2 \mathrm{mM}$. Cell viability was higher than $95 \%$ at this ALA concentration range according to the MTT assays. The addition of PK 11195 in the medium together with ALA reduced the ALA-induced PPIX synthesis as assessed by flow cytometry and confirmed by spectral fluorimetry (Figure 3B). The effect of PK 11195 on the ALA-induced intracellular porphyrin fluorescence was dose dependent. The apparent affinity for PK 11195 , close to $0.1 \mathrm{mM}$, could be extrapolated from inhibition data (Figure 3C). This low affinity in the micromolar range is in agreement with that previously described for TSPO2 (Fan et al., 2009) which is very different with the nanomolar affinity of mitochondrial TSPO1 for PK 11195 (Ostuni et al., 2009).

We then tested in UT-7 whether PK 11195 decreased porphyrins accumulation by the inhibition of one of the enzymes of the heme biosynthesis. We measured the accumulation of different heme synthesis intermediates within the cells and observed a proportional reduction of uroporphyrin, coproporphyrin and PPIX in the presence of increasing concentration of PK 11195 (Figure 3D). A similar decrease in heme synthesis intermediates was observed in cell culture medium when UT-7 cells were treated with PK 11195 (Figure 3E). Thus, we concluded that PK 11195 did not modify the activity of the enzymes of heme biosynthesis. We also determined that PK 11195 did not reduced PPIX accumulation by increasing export of intermediates.

Another potential role of PK 11195 could be related to a lowering of the ALA conversion into non-fluorescent pyrrole PBG (porphobilinogen) by the inhibition of the 5-aminolevulinic acid deshydratase (ALAD). Thus, we measured the ALAD activity (Figure 4A) and observed that PK 11195 did not affect the ALAD enzymatic activity. One may also imagine that PK 11195 might accelerate the PPIX transformation into heme acting on ferrochelatase (FECH). FECH activity was examined by aerobic formation of zinc-mesoporphyrin in cell lysates in the 
presence of PK 11195 (Figure 4B) and no difference were observed showing that PK 11195 did not affect the FECH enzymatic activity.

\section{TSPO2 is a transporter of ALA}

To get an insight into the specificity of ALA transport by TSPO2, we used another heme precursor, PBG that induces PPIX accumulation but in lower amounts in human fibroblasts (Johansson et al., 2003). PBG, as well as ALA induced endogenous porphyrins synthesis in UT-7 (Figure 5). PBG concentration was linearly correlated with PPIX accumulation (Figure 5A), but not affected by PK 11195 (Figure 5B). The main intermediate is URO whose concentration remains constant in the presence of PK 11195 both within the cells and in the cell culture medium (Figure 5C and 5D). This could suggest that PBG boosted the heme biosynthesis with an accumulation of URO in excess that was secreted outside the cells.

To further characterize the specificity of TSPO2 transporter, we checked the effect of ALA competitors including GABA and amino acids (Smith et al., 1999; Rud et al., 2000). L-leucine and L-citruline at the same concentration that ALA were not competitor of ALA-induced PPIX accumulation, whereas GABA reduced by $50 \%$ the effect of ALA, similarly to that observed for PK 11195 (Figure 6A). This suggests that ALA entered the UT-7 cells by amino acids transporters, but also that only the closest structural analogs (ALA and GABA) were competitors.

TSPO1 is present in the UT-7 cells and could be impacted as well as TSPO2 by the addition of PK 11195. We observed (Figure 6B) that PK 11195 changed the intracellular ratio of ZnPPIX over free PPIX (20\% non-treated cells vs. $70 \%$ treated with $60 \mu \mathrm{M}$ PK 11195) as previously described for ALA treated rat pancreatoma cells (Mesenholler and Matthews, 2000) It suggests that the enzymatic activity of ferrochelatase was not inhibited by PK 11195 and that ferrochelatase catalyzes an insertion of $\mathrm{Zn}^{2+}$ into porphyrin ring. 
To confirm the role of TSPO2 as an ALA transporter, we transfected K562 cells with EGFPTSPO2 to generate over-expression of TSPO2. The efficiency of transfection was ranging from 55 to $80 \%$ (Figure 7A) and a significant increase in TSPO2 mRNA level was confirmed by qPCR (Figure 7B). We observed a $45 \mathrm{kDa}$ protein corresponding to the over-expression of recombinant EGFP-TSPO2 by Western blot using both anti-TSPO2 and anti-GFP antibodies (Figure 7C). TSPO2 was mostly located at the endoplasmic reticulum, probably in the Golgi but also at the plasma membrane 16 hours after transfection (Figure 7D). ALA addition for the following $4 \mathrm{~h}$ did not change the localisation of the recombinant protein at the plasma membrane (Figure 7D). We quantify PPIX accumulation by flow cytometry in transfected (GFP positive) and non-transfected (GFP negative) cells from the same culture incubated $4 \mathrm{~h}$ with 0.5 or $1 \mathrm{mM}$ ALA. As expected, ALA-induced PPIX accumulation was observed in both cell populations (Figure 7E). Cells over-expressing TSPO2 (GFP positive) exhibited higher concentrations of PPIX than non-transfected (GFP negative) cells as shown by the increase of the median of fluorescence of the PPIX (Figure 7F). The percentage of cells that respond to the ALA stimulation was also higher (almost $30 \%$ ) for transfected cells than for the nontransfected ones (Figure 7G). This suggests that the over expression of TSPO2 at the plasma membrane fasten PPIX synthesis caused by an increased uptake of ALA.

\section{$\underline{\text { Discussion }}$}

We aimed to determine whether TSPO play a role in the ALA incorporation in human erythroleukemia cells. Among the various steps of heme biosynthesis (Supplementary Figure S1) and regulation, numerous transporters have been involved both in eukaryotes and prokaryotes cells. ALA transport across membrane remains one of the less characterized processes. 
We showed that PPIX accumulation in erythroleukemia cells was not linearly proportional to ALA concentration, but showed an onset at $0.2 \mathrm{mM}$ for both K562 and UT-7 cells. This result was in agreement with previously published studies (Berg et al., 1996) on human adenocarcinoma cells and hamster lung fibroblasts that showed an onset close to 0.1 and $0.025 \mathrm{mM}$, respectively for ALA-induced PPIX accumulation. In erythroleukemia cells, this might be due to the implication of a plasma membrane transporter that has an affinity for ALA close to $0.2 \mathrm{mM}$ and that is inhibited by a TSPO high-affinity ligand. It has been suggested that PPIX did not accumulate at low ALA concentration because ferrochelatase would be able to convert all PPIX into heme (Berg et al., 1996). This has been confirmed by heme synthesis detected at ALA concentration as low as $0.01 \mathrm{mM}$ in K562 cells (Fujiwara et al., 2014).

Two mechanisms have been described to date for the ALA entry into the cells (BermudezMoretti et al., 2002): (i) a passive diffusion and (ii) a transporter acting at different rates and concentrations. Passive diffusion can be excluded since such a mechanism should give a linear concentration dependence for ALA-induced PPIX accumulation, only governed by the concentration gradient, and our data showed a non linear dependence with a concentration onset. Among the different transporters of ALA described in the literature, there seems to be a tissue specificity. Indeed, PEPT1 participated in the intestinal permeability, and oral absorption of ALA in mice (Xie et al., 2016), whereas PEPT2 is involved in the reabsorption of ALA from the glomerular filtrate in the human renal proximal tubule cells (Tchernitchko et al., 2016). PEPT2 is also involved in ALA uptake in mouse neonatal astrocytes (Xiang et al., 2006). ALA uptake by these transporters occurs by $\mathrm{pH}$ gradient-dependent electrogenic symport, and it is shared by di- and tri-peptides, as natural substrates (Doring et al., 1998). ALA uptake by these transporters is not abrogated by its close structural analogue GABA. Our data suggest that neither PEPT1 nor PEPT2 is involved in ALA uptake in both K562 and 
UT-7 cells since we observed an apparent inhibitory effect of GABA on ALA-induced PPIX accumulation.

PAT1 mediates the apical absorption of ALA in intestinal cells Caco-2, this uptake is $\mathrm{pH}$ dependent (Frolund et al., 2010), but Na independent. PAT1 is a proton-coupled amino acid transporter specialized for small zwiterionic amino acids. BETA transporter superfamily that mainly includes GABA neurotransmitter transporters GAT are not only involved in GABA uptake but also ALA uptake in various human and murine adenocarcinoma cells (Rud et al., 2000; Bermudez Moretti et al., 2002). Transport of ALA is Na, and partly Cl-dependent. Transport is inhibited by zwitterionic, and basic amino acids with a basic function (Rud et al., 2000). Since amino acids have no effect on our ALA-induced PPIX accumulation in erythroleukemia cells, we believe that the ALA transporter in those cells is neither PAT1 nor BETA transporter.

We propose that the uptake of ALA in our cell system might be through TSPO2 since it is profoundly affected by a TSPO ligand, the PK 11195. Although the effects of PK 11195 were significant, it does not totally stop ALA-induced PPIX accumulation, suggesting that some other proteins could also be involved in ALA transport. Over expression of TSPO2 significantly increases ALA induced PPIX accumulation, confirming the involvement of TSPO2 in ALA uptake. This is the first description of a binding and transport of ALA by TSPO2. Only PPIX and heme have been described as PK 11195 competitor in cells with nanomolar affinities (Verma et al., 1988). Structural studies of bacterial TSPO showed that PPIX binds to the same site that the PK 11195 (Guo et al., 2015; Li et al., 2015). The binding cavity changes to adapt to various ligand (Lacapere et al., 2019). It has been described that ALA has a very low affinity for TSPO1 in the millimolar range as measured by competition with PK 11195 that has a very high affinity in the nanomolar range (Verma et al., 1988). One may imagine that TSPO2 exhibits closer affinity for ALA and PK 11195 in the micromolar 
range, thus suggesting a competitive mechanism for the inhibition of ALA-induced PPIX accumulation in the presence of PK 11195. In other words, PK 11195 could block the entry of ALA in the cells through TSPO2, rather than favoring the export of intermediates of the heme biosynthesis pathway as previously described for Rhodobacter sphaeroides TSPO1 in the presence of ALA (Yeliseev et al., 1999).

The accumulation of different porphyrins depends both on the cell type and the PPIX inducer. It has been reported that uptake of ALA was responsible for increasing uroporphyrin, coproporphyrin, and PPIX accumulation (Ohgari et al., 2005). In our experiments, K562 cells were less prone to PPIX accumulation than UT-7 cells, suggesting that ALA-uptake was higher in UT-7 than in K562 cells, or that the heme enzymatic machinery was more efficient in UT-7 cells. In K562 cells, ALA induced essentially PPIX accumulation inside the cells, while in the cell culture medium, coproporphyrin was the main intermediate detected with only traces of PPIX and uroporphyrin. In UT-7 cells, ALA induces the accumulation of PPIX in both intracellular and extracellular compartments. Whereas PBG leads to a high accumulation of intracellular uroporphyrin and PPIX, and to the exclusive efflux of uroporphyrin from the UT-7 cells. These results suggest the presence of different ALA transporters in K562 and UT-7 cells, mainly one for uroporphyrin in UT-7 cells and one for coproporphyrin in K562 cells.

The Figure 8 presents a schematic overview of the biosynthesis and the transport of heme intermediates induced by the addition of exogenous ALA.

ALA-mediated PPIX synthesis depends on active ALA uptake and effective transport of different porphyrin metabolites by porphyrin transporters that are critical regulators of heme synthesis. After exogenous administration of ALA, accumulation of PPIX occurred more markedly in certain tumor cells than in normal cells. This effect has been explained by an 
increased activity of porphobilinogen deaminase (Navone et al., 1991) and limited activity of ferrochelatase (Van Hillegersberg et al., 1992) in the heme biosynthetic pathway.

According to Fujiwara at al., (2014), ALA supplementation could be an effective therapeutic strategy to restore heme synthesis in congenital sideroblastic anemia (CSA) associated with ALAS2 defects. ALA treatment resulted in a significant dose-dependent increase of heme in the K562 cell line. The authors proposed that ALA may be transported into erythroid cells by PAT1 based on the competitive inhibition of ALA uptake by GABA addition. However, siRNA-knockdown of PAT1 did not show modified ALA uptake and thus did not confirm the implication of PAT1 (Fujiwara at al., 2014). Conversely, they find the up-regulation of the TSPO2 gene (2.4-fold induction) in K562 after treatment with $0.5 \mathrm{mM}$ ALA, suggesting that TSPO2 might be involved in ALA uptake.

The present results provide new insights into the biochemical characterization and molecular mechanisms involved in ALA uptake in erythoid cells. It has been proposed that ALA, which is overproduced in inherited acute hepatic porphyrias, may be responsible for the neurological symptoms. (Bissell at al., 2017, Puy at al., 2010). In a future study, we will focus on the ALA efflux from the hepatic cells and its uptake by neuronal cells and the possible implication of TSPO into it. Knowledge of the mechanisms by which ALA enters into neuronal cells is mandatory in understanding the potential neurotoxic role of ALA during the acute attack of porphyria in patients.

\section{Materials and methods}

\section{Chemistry}

ALA, PBG, GABA, L-citrulline, L-leucine, PK 11195 were all purchased from Sigma Aldrich (France). PBG was dissolved in alkaline PBS with $\mathrm{pH}$ adjusted at 8.0. L-leucine and PK 11195 was dissolved in DMSO. L-citrulline was dissolved in PBS. All other chemicals were 
dissolved in sterile distilled water to a concentration of $0.3 \mathrm{mM}$. Each stock solution was kept in the dark at $-20{ }^{\circ} \mathrm{C}$.

\section{Cell cultures}

EPO-dependent UT-7 cells were grown in MEM alpha medium (ThermoFischer, France), supplemented with $10 \%$ fetal calf serum, $1 \%$ antibiotics penicillin, streptomycin, and 2 UI/mL erythropoietin (Janssen, France). K562 cells were maintained in RMPI 1640 medium (ThermoFischer, France), supplemented with $10 \%$ fetal calf serum and $1 \%$ antibiotics penicillin-streptomycin. The cells were incubated at $37^{\circ} \mathrm{C}$ in a humidified atmosphere with $5 \% \mathrm{CO}_{2}$ and $95 \%$ air.

K562 in exponential phase was transfected by electroporation (Amaxa, Nucleofector Kit V, France) with EGFP-hTSPO2 plasmid (Fan et al., 2009) (generous gift from V. Papadopoulos) that express full ORF of human TSPO2 tagged with EGFP at the N-terminal part. Cell viability, 16, 20, 24 and 36 hours after transfection was tested using 7-ADD to select the best conditions.

\section{Cellular PPIX analysis by flow cytometry}

All treatments were performed in the dark. Cells $\left(5 \times 10^{5}\right)$ were treated with different concentrations of $\mathrm{ALA}$ or $\mathrm{PBG}$ at $37^{\circ} \mathrm{C}$, in the presence or absence of $\mathrm{PK} 11195$ for $24 \mathrm{~h}$, harvested by centrifugation, washed twice with PBS supplemented with $0.5 \%$ bovine serum albumin. PPIX was measured in 10,000 cells per sample using a Becton Dickinson LSR Fortessa $^{\mathrm{TM}}$ cell analyzer with an excitation wavelength of $405 \mathrm{~nm}$ and emission wavelength $655 \mathrm{~nm}$ and quantified by FlowJo software.

In TSPO2 over-expressing experiments, $16 \mathrm{~h}$ after transfection, cells were challenged with 0.5 or $1 \mathrm{mM}$ ALA for $4 \mathrm{~h}$.

\section{Specific porphyrin analysis}

\section{Total porphyrin quantification}


Cell pellets $\left(3 \times 10^{6}\right)$ were homogenized in $\mathrm{NaCl} 0.9 \%$ and sonicated. Protein concentration was determined using Coomassie Blue reagent (Bio-Rad Protein assay). Total porphyrins were extracted from cell pellets and culture medium using ether-acetic acid (4:1 v/v). After centrifugation, $\mathrm{HCl}$ was added to the supernatant at a final concentration of $1 \mathrm{M}$. After mixing, the lower acid layer was collected. The total porphyrin fluorescence was detected at room temperature by spectrofluorimetric recording the excitation spectrum from $380 \mathrm{~nm}$ to $440 \mathrm{~nm}$ and measuring the emitted fluorescence at $602 \mathrm{~nm}$. The concentration of porphyrins was estimated to standard calibration.

\section{Specific porphyrin quantification}

Porphyrins isolated from the cell pellets and culture medium were transformed into methyl esters by reaction of an aqueous acid extract of porphyrins with methanol-sulphuric acid $(95: 5 \mathrm{v} / \mathrm{v})$ in the dark at room temperature. Porphyrins methyl esters were extracted by adding chloroform and separated by normal-phase adsorption chromatography on a polar column (Silica, $10 \mu \mathrm{m}, 30 \mathrm{~cm} \times 3.9 \mathrm{~mm}$; Waters $\mu$ Porasil) using a gradient of organic solvents (cyclohexane - ethyl acetate ranging from 38/62 to 60/40 v/v) for elution. The retention times increased as the number of ester side chains increase. The detection was performed at room temperature by a fluorescence detector with excitation wavelength $400 \mathrm{~nm}$ and emission wavelength at $630 \mathrm{~nm}$.

\section{Determination of zinc-protoporphyrin percentage}

Cell pellets $\left(3 \times 10^{6}\right)$ were homogenized in $\mathrm{NaCl} 0.9 \%$ and sonicated. A solution of Ethanol$\mathrm{H}_{2} \mathrm{O}(19: 1 \mathrm{v} / \mathrm{v})$ was added, the sample was centrifuged, and the supernatant was analyzed by spectrofluorimetry at room temperature. The emission fluorescence spectrum was recorded from $550 \mathrm{~nm}$ to $670 \mathrm{~nm}$ with the excitation set at $415 \mathrm{~nm}$. The ratio of ZnPPIX over free PPIX was determined to measure the intensity of the two peaks around 580 and $635 \mathrm{~nm}$.

\section{Immunofluorescence labeling}


Cultured cells $\left(0.15 \times 10^{5}\right)$ were washed twice in PBS and cytospined onto slides. Then, cells were fixed by $3 \%$ para-formaldehyde for $15 \mathrm{~min}$, quenched for $10 \mathrm{~min}$ in $20 \mathrm{mM}$ glycine, permeabilized for $20 \mathrm{~min}$ in $0.1 \%$ saponin, and blocked in PBS containing $3 \%$ BSA and $0.1 \%$ saponin for $20 \mathrm{~min}$ at room temperature. Primary antibody anti-hTSPO2 (1/200) (Marginedas-Freixa et al., 2016) was added in the same blocking buffer for $1 \mathrm{~h}$. Cells were washed three times in PBS and incubated for one hour with anti-rabbit Alexa 488 (1/200) and Hoechst dye $(1 / 1,000)$. After three washes, cells were mounted with mounting medium GB Mount (GBI labs). The observation was performed at room temperature using an oilimmersion X63 objective on a laser scanning confocal Zeiss LSM 780 microscope. TSPO2 was excited by the $488 \mathrm{~nm}$ laser and Hoechst dye by $405 \mathrm{~nm}$ line of a diode laser and zoom X2. Negative controls were performed incubating cells in the absence of an anti-TSPO2 antibody.

EGFP-TSPO2 localization was observed by following EGFP localization, and mitochondria were labelled with $5 \mathrm{nM}$ Mitotracker Deep Red, $30 \mathrm{~min}, 37^{\circ} \mathrm{C}$. After resuspension in PBS, pictures were taken at room temperature with a Zeiss Oxiobserver Z1 fluorescent microscope equipped with a high-resolution AxioCam MRm Rev.3 camera and AxioVision 4 analysis software (Carl Zeiss) using a Plan-Apochromat 40x/0.95 Korr M27 objective. Green and red fluorescent cells were visualized using the Colibri LED 470, and $620 \mathrm{~nm}$ modules (Carl Zeiss), respectively.

\section{ALAD enzymatic activity assay}

UT-7 cells $\left(30 \times 10^{6}\right)$ were either treated or not with $60 \mu \mathrm{M}$ PK 11195 for $24 \mathrm{~h}$; cell pellets were washed by $0.9 \% \mathrm{NaCl}$ and frozen. ALAD activity was assayed by determining the content of PBG formed. Cells were lysed in $50 \mathrm{mM}$ sodium phosphate buffer, $\mathrm{pH}$ 6.3. $40 \mathrm{mM}$ dithiotreitol and $10 \mathrm{mM}$ ALA were added. The mixture was incubated for $60 \mathrm{~min}$ at $37^{\circ} \mathrm{C}$. The reaction was stopped by the addition of $20 \mathrm{mM}$ mercury chloride in $10 \%(\mathrm{w} / \mathrm{v})$ 
trichloroacetic acid. A centrifugation step followed for $5 \mathrm{~min}$ at 2,000g. The supernatant was mixed 1:1 with Ehrlich's reagent and analyzed after 15 min spectrophotometrically at $553 \mathrm{~nm}$ against a blank. The amount of PBG that has reacted with Ehrlich's reagent was estimated using the extinction coefficient of $6.1 \times 10^{4} \mathrm{M}^{-1} \mathrm{~cm}^{-1}$. The activity was then expressed in nmol $\mathrm{PBG} / \mathrm{h} / \mathrm{mg}$ protein.

\section{Ferrochelatase enzymatic activity assay}

UT-7 cells $\left(5 \times 10^{6}\right)$ were treated or not with $60 \mu \mathrm{M}$ PK 11195 for $24 \mathrm{~h}$; cell pellets were washed by $0.9 \% \mathrm{NaCl}$ and ferrochelatase activity was analyzed. Ferrochelatase is the terminal enzyme in the heme biosynthesis pathway that catalyzes the insertion of $\mathrm{Fe}^{2+}$ into the PPIX ring to form heme. In the absence of iron and under aerobic conditions, the FECH will use zinc as a substitute. The activity of FECH was measured by aerobic enzymatic formation of zinc-mesoporphyrin IX in cell lysates ( $\mathrm{Li}$ et al., 1987). Production of zinc-mesoporphyrin is detected by spectrofluorimetry (excitation at $410 \mathrm{~nm}$ and emission at $580 \mathrm{~nm}$ ).

\section{Quantitative real-time PCR}

Total RNA was extracted using the RNAeasy Mini Kit (Qiagen). cDNA was generated from $2 \mathrm{mg}$ of total RNA using the High Capacity cDNA synthesis Kit (Applied Biosystems). 2 ng of cDNA was amplified per reaction and each reaction was performed in two technical replicates using the C1000 TouchTM Thermal Cycler (Biorad) with SYBR ${ }^{\circledR}$ Premix Taq ${ }^{\mathrm{TM}}$ II (Takara) (TSPO2 sequence : 5'-TCACGAGTGAACAGCCAGAC-3' and 5'TCTTCAAGGTGAATGCGGCT-3'). Gene expression was normalized to the expression of Tata box Binding Protein (TBP) (Prime Time ${ }^{\circledR}$ qPCR Assay, Hs.PT.58.19838260, Integrated DNA Technology), and relative expression was assessed using the efficiency corrected calculation model (Pfaffl, 2004).

\section{Western blotting analysis}


$30 \mu \mathrm{g}$ of protein extracts were loaded on SDS-polyacrylamide gel (4-12.5\%; NuPAGE, Life Technology), and analyzed by Western blotting. The following antibodies were used: rabbit pre-immune serum (1/500), rabbit anti-hTSPO2 raised against $13 \mathrm{C}$-terminal residues of hTSPO2 (1/500; Eurogentec, Angers, France), anti-GFP (1/1,000; A6455, Life Technology) and anti- $\beta$-actin HRP (1/3,000; Cell Signaling Technology, 13E5), mouse anti-GPA (alpha) clone E4 (Sigma Aldrich, France).

\section{Subcellular fractioning}

Cell pellets $\left(5 \times 10^{7}\right)$ were suspended in a $5 \mathrm{mM}$ Tris, $1 \mathrm{mM}$ EDTA, $250 \mathrm{mM}$ sucrose buffer and mechanically disrupted and homogenized (glass/Teflon Potter) for $30 \mathrm{~min}$ at $4^{\circ} \mathrm{C}$. A protease inhibitor cocktail (Roche) was added to preserve samples. Successive centrifugations were performed to isolate subcellular membranous fractions, (i) at $1,000 \mathrm{~g}$ for $10 \mathrm{~min}$ at $4{ }^{\circ} \mathrm{C}$, allowing isolation of the nucleus fraction in the pellet. (ii) The supernatant was further centrifuged at 20,000 $\mathrm{g}$ for $10 \mathrm{~min}$ at $4^{\circ} \mathrm{C}$ for isolation of mitochondrial fractions in the pellet, and (iii) at $27,000 \mathrm{~g}$ for $10 \mathrm{~min}$ at $4^{\circ} \mathrm{C}$ for isolation of reticulum / golgi fractions in the pellet and (iv) finally at $200,000 \mathrm{~g}$ for $1 \mathrm{~h}$ at $4^{\circ} \mathrm{C}$ for isolation of plasma membranes. Fractions were further suspended in a $5 \%$ SDS lysis buffer and analyzed in electrophoresis in denaturing conditions, using the antibodies described above.

\section{Author contribution}

Concept and design of the research: HM, SDL, KP, HP, MAO, LG and JJL.

Carrying out the experimental work: HM, SDL, AM, HRS, CH and CS.

Data analysis and interpretation: HM, SDL, MAO, LG and JJL.

Writing of the article: HM, SDL, MAO and JJL.

\section{Acknowledgment}


We are grateful to Sylvie Simonin and Camille Jamet for their excellent technical expertise; Samira Benadda (Plateforme Imagerie cellulaire et tissulaire CRI) for confocal image acquisition and Plateforme de Cytometrie en flux CRI. We are grateful to Irene MarginedasFreixa for initial scientific discussion.

\section{Funding}

This study was supported by grants from Laboratory of Excellence GR-Ex, reference ANR11-LABX-0051. The labex GR-Ex is funded by the program "Investissements d'avenir" of the French National Research Agency, reference ANR-18-IDEX-0001. HRS was supported by a scholarship "Club du Globule rouge et du fer".

\section{Conflict of interest statement}

The authors declare no conflict of interest.

\section{References}

An, X., Schulz, V.P., Li, J., Wu, K., Liu, J., Xue, F., Hu, J., Mohandas, N. and Gallagher, P.G. (2014) Global transcriptome analyses of human and murine terminal erythroid differenciation. Blood 123(22), 3466-3477.

Berg, K., Anholt, H., Bech, O. and Moan, J. (1996) The influence of iron chelators on the accumulation of protoporphyrin IX in 5-aminolaevulinic acid-treated cells. Br. J. Cancer 74(5), 688-97.

Bermúdez Moretti, M, Correa García, S.R., Chianelli, M.S., Ramos, E.H., Mattoon, J.R and Batlle, A. (1995) Evidence that 4-aminobutyric acid and 5-aminolevulinic acid share a 
common transport system into Saccharomyces cerevisiae. Int. J. Biochem. Cell. Biol. 27(2):169-73.

Bermúdez Moretti, M., Correa García, S.R., Ramos, E.H. and Batlle, A. (1996) DeltaAminolevulinic acid uptake is mediated by the gamma-aminobutyric acid-specific permease UGA4. Cell. Mol. Biol. (Noisy-le-grand). 42(4), 519-23.

Bermúdez Moretti, M., Correa Garcían, S.R., Perotti, C, Batlle, A and Casas, A. (2002) DeltaAminolevulinic acid transport in murine mammary adenocarcinoma cells is mediated by beta transporters. Br. J. Cancer 87(4), 471-4.

Bissell, D.M., Anderson, K.E. and Bonkovsky, H.L. (2017) Porphyria. N. Engl. J. Med. 377, 862-872.

Chiabrando, D., Marro, S., Mercurio, S., Giorgi, C., Petrillo, S., Vinchi, F., Fiorito, V., Fagoonee, S., Camporeale, A., Turco, E., Merlo, G.R., Silengo, L., Altruda, F., Pinton, P. and Tolosano, E. (2012) The mitochondrial heme exporter FLVCR1b mediates erythroid differentiation. J. Clin. Invest. 122(12), 4569-79.

Döring, F., Walter, J., Will, J., Föcking, M., Boll, M., Amasheh, S., Clauss, W. and Daniel, H. (1998) Delta-aminolevulinic acid transport by intestinal and renal peptide transporters and its physiological and clinical implications. J. Clin. Invest. 101, 2761-2767. 
Fan, J, Rone, M.B. and Papadopoulos, V. (2009) Translocator protein 2 is involved in cholesterol redistribution during erythropoiesis. J. Biol. Chem. 284(44), 30484-97.

Frølund, S., Marquez, O.C., Larsen, M., Brodin, B. and Nielsen, C.U. (2010) Deltaaminolevulinic acid is a substrate for the amino acid transporter SLC36A1 (hPAT1). Br. J. Pharmacol. 159(6), 1339-53.

Fujiwara, T., Okamoto, K., Niikuni, R., Takahashi, K., Okitsu, Y., Fukuhara, N., Onishi, Y., Ishizawa, K., Ichinohasama, R., Nakamura, Y., Nakajima, M., Tanaka, T. and Harigae, H. (2014) Effect of 5-aminolevulinic acid on erythropoiesis: a preclinical in vitro characterization for the treatment of congenital sideroblastic anemia. Biochem. Biophys. Res. Commun. 454(1), 102-8.

Guo, Y., Kalathur, R.C., Liu, Q., Kloss, B., Bruni, R., Ginter, C., Kloppmann, E., Rost, B. and Hendrickson, W.A. (2015) Protein structure. Structure and activity of tryptophan-rich TSPO proteins. Science $\mathbf{3 4 7}, 551-555$.

Ishikawa, T., Takahashi, K., Ikeda, N., Kajimoto, Y., Hagiya, Y., Ogura, S.I., Miyatake, S.I. and Kuroiwa, T. (2011) Transporter-Mediated Drug Interaction Strategy for 5-Aminolevulinic Acid (ALA)-Based Photodynamic Diagnosis of Malignant Brain Tumor: Molecular Design of ABCG2 Inhibitors. Pharmaceutics 3(3), 615-635.

Ishizuka, M., Abe, F., Sano, Y., Takahashi, K., Inoue, K., Nakajima, M., Kohda, T., Komatsu, N., Ogura, S.I. and Tanaka, T. (2011) Novel development of 5-aminolevulinic acid (ALA) in cancer diagnoses and therapy. Int. Immunopharmacol. 11, 358-365. 
Jahansson, A., Möller, C. and Harper, P. (2003) Correction of the biochemical defect in porphobilinogen deaminase deficient cells by non-viral gene delivery. Mol. Cell. Biochem. 250(1-2), 65-71.

Keel, S.B., Doty, R.T., Yang, Z., Quigley, J.G., Chen, J., Knoblaugh, S., Kingsley, P.D., De Domenico, I., Vaughn, M.B., Kaplan, J., Palis, J. and Abkowitz, J.L. (2008) A heme export protein is required for red blood cell differentiation and iron homeostasis. Science 319(5864), $825-8$.

Kobuchi, H., Moriya, K., Ogino, T., Fujita, H., Inoue, K., Shuin, T., Yasuda, T., Utsumi, K. and Utsumi, T. (2012) Mitochondrial localization of ABC transporter ABCG2 and its function in 5-aminolevulinic acid-mediated protoporphyrin IX accumulation. PLoS One 7(11), e50082.

Komatsu, N., Yamamoto, M., Fujita, H., Miwa, A., Hatake, K., Endo, T., Okano, H., Katsube, T., Fukumaki, Y., Sassa, S. and Miura, Y. (1993) Establishment and characterization of an erythropoietin-dependent subline UT-7/Epo, derived from human leukemia cell line, UT-7. Blood 82(5), 456-464.

Krishnamurthy, P.C., Du, G., Fukuda, Y., Sun, D., Sampath, J., Mercer, K.E., Wang, J., SosaPineda, B., Murti, K.G. and Schuetz, J.D. (2006) Identification of a mammalian mitochondrial porphyrin transporter. Nature 443(7111), 586-9. 
Lacapere, J.-J., Duma, L., Finet, S., Kassiou, M. and Papadopoulos, V. (2019) Insight into the structural features of TSPO: implications for drug development. Trends Pharmacol. Sci. doi.org/10.1016/j.tips.2019.11.005.

Li, F., Liu, J., Zheng, Y., Garavito, R.M. and Ferguson-Miller, S. (2015) Protein structure. Crystal structures of translocator protein (TSPO) and mutant mimic of a human polymorphism. Science 347, 555-558.

Li, F.M., Lim, C.K. and Peters, T.J. (1987) An HPLC assay for rat liver ferrochelatase activity. Biomed Chromatogr. 2(4),164-8.

Lin, Y.H., Chang, H.M., Chang, F.P., Shen, C.R., Liu, C.L., Mao, W.Y., Lin, C.C., Lee, H.S. and Shen, C.N. (2013) Protoporphyrin IX accumulation disrupts mitochondrial dynamics and function in ABCG2-deficient hepatocytes. FEBS Lett., 587, 3202-3209.

Malik, Z., Lugaci, H. and Hanania, J. (1988) Stimulation of Friend erythroleukemic cell cytodifferentiation by 5-amino levulinic acid; porphyrins, cell size, segregation of sialoglycoproteins, and nuclear translocation. Exp. Hematol. 16(5), 330-5.

Marginedas-Freixa, I., Hattab, C., Bouyer, G., Halle, F., Chene, A., Lefevre, S.D., Cambot, M., Cueff, A., Schmitt, M., Gamain, B., Lacapere, J.-J., Egee, S., Bihel, F., Le Van Kim C. and, Ostuni, M.A. (2016) TSPO ligands stimulate ZnPPIX transport and ROS accumulation leading to the inhibition of P. falciparum growth in human blood. Sci. Rep. 6, 33516. 
McHale, C.M., Winter, P.C. and Lappin, T.R.J. (1999) Erythroid gene expression is differentially regulated by erythropoietin, haemin and delta-aminolevulinic acid in UT-7 cells. Br. J. Haematology 104, 829-837.

Mesenholler, M. and Mathews, E.K. (2000) A key role for the mitochondrial benzodiazepine receptor in cellular photosensitisation with delt-aminolevulinic acid. Eur. J. Pharmacol. 406(2), 171-180.

Navone, N.M., Polo, C.F., Frisardi A.L. and Batlle A.M. (1991) Mouse mammary carcinoma porphobilinogenase and hydroxymethylbilane synthetase. Comp. Biochem. Physiol. B98, 6771.

Ohgari, Y., Nakayasu, Y., Kitajima, S., Sawamoto, M., Mori, H., Shimokawa, O., Matsui, H. and Taketani, S. (2005) Mechanisms involved in d-aminolevulinic acid (ALA)-induced photosensitivity of tumor cells: Relation of ferrochelatase and uptake of ALA to the accumulation of protoporphyrin. Biochem. Pharmacol. 71, 42-49.

Ostuni, M.A., Peranzi, G., Ducroc, R., Fasseu, M., Vidic, B., Dumont, J., Papadopoulos, V. and Lacapère, J.-J. (2009) Distribution, pharmacological characterization and function of the translocator protein peripheral-type benzodiazepine receptor in rat intestine. Biol. Cell 101(10), 573-586.

Papadopoulos, V., Baraldi, M., Guilarte, T.R., Knudsen, T.B., Lacapère, J.-J., Lindemann, P., Norenberg, M.D., Nutt, D., Weizman, A., Zhang, M.R. and Gavish, M. (2006) Translocator 
protein $(18 \mathrm{kDa})$ : new nomenclature for the peripheral-type benzodiazepine receptor based on its structure and molecular function. Trends Pharmacol. Sci. 27(8), 402-9.

Pfaffl, M.W. (2004) Quantification strategies in real-time PCR. In: A-Z of Quantitative PCR, (Bustin SA ed), pp. 87-120. La Jolla, CA: IUL Biotechnology Series, International University Line.

Puy, H., Gouya, L. and Deybach, J.-C. (2010) Porphyrias. Lancet 375, 924-937.

Rud, E., Gederaas, O., Hogset, A. and Berg, K. (2000) 5-aminolevulinic acid, but not 5aminolevulinic acid esters, is transported into adenocarcinoma cells by system BETA transporters. Photochem. Photobiol. 71, 640-647.

Smith, M.W., Tyreman, D.R., Payne, G.M., Marshall, N.J. and Payne, J.W. (1999) Substrate specificity of the periplasmic dipeptide-binding protein from Escherichia coli: experimental basis for the design of peptide prodrugs. Micobiology 145, 2891-2901.

Taketani, S., Kohno, H., Furukawa, T. and Tokunaga, R. (1994) Induction of peripheral-type benzodiazepine receptors during differenciation of mouse erythroleukemia cells. J. Biol. Chem. 269(10), 7527-7531.

Taketani, S., Kohno, H., Furukawa, T. and Tokunaga, R. (1995) Involvement of peripheraltype benzodiazepine receptors in the intracellular transport of heme and porphyrins. J. Biochem. 117, 875-880. 
Verma, A. and Snyder, S.H. (1988) Characterization of porphyrin interactions with periheral type benzodiazepine receptors. Mol. Pharmacol. 84, 2256-2260.

Tchernitchko, D., Tavernier, Q., Lamoril, J., Schmitt, C., Talbi, N., Lyoumi, S., Robreau, A.M., Karim, Z., Gouya, L., Thervet, E., Karras, A., Puy, H. and Pallet, N. (2016) Variant of Peptide Transporter 2 Predicts the Severity of Porphyria-Associated Kidney Disease. J. Am. Soc. Nephrol. 28(6), 1924-1932.

Van Hillegersberg, R., Van den Berg, J.W., Kort, W.J., Terpstra, O.T. and Wilson J.H. (1992) Selective accumulation of endogenously produced porphyrins in a liver metastasis model in rats. Gastroenterology 103, 647-651.

Verkamp, E., Backman, V.M., Bjornsson, J.M., Soll, D. and Eggertsson, G. (1993) The periplasmic dipeptide permease system transports 5-aminilevulinic acid in Escherichia coli. J. bacteriol. 175(5), 1452-1456.

Xiang, J., Hu, Y., Smith, D.E. and Keep, R.F. (2006) PEPT2-mediated transport of 5aminolevulinic acid and carnosine in astricytes. Brain Res. 1122, 18-23.

Xie, Y., Hu, Y. and Smith, D.E. (2016) The proton-coupled oligopeptide transporter 1 plays a major role in the intestinal permeability and absorption of 5-aminolevulinic acid. Br. J. Pharamacol. 173(1), 167-176. 
Yeliseev, A.A. and Kaplan, S. (1999) A novel mechanism for the regulation of photosynthesis gene expression by the TspO outer membrane protein of Rhodobacter sphaeroides 2.4.1. J. Biol. Chem. 274, 21234-21243

Yien, Y.Y., Robledo, R.F., Schultz, I.J., Takahashi-Makise, N., Gwynn, B., Bauer, D.E., Dass, A., Yi, G., Li, L., Hildick-Smith, G.J., Cooney, J.D., Pierce, E.L., Mohler, K., Dailey, T.A., Miyata, N., Kingsley, P.D., Garone, C., Hattangadi, S.M., Huang, H., Chen, W., Keenan, E.M., Shah, D.I., Schlaeger, T.M., DiMauro, S., Orkin, S.H., Cantor, A.B., Palis, J., Koehler, C.M., Lodish, H.F., Kaplan, J., Ward, D.M., Dailey, H.A., Phillips, J.D., Peters, L.L. and Paw, B.H. (2014) TMEM14C is required for erythroid mitochondrial heme metabolism. J. Clin. Invest. 124(10), 4294-304. 


\section{Figure Legends}

Figure 1: Effect of ALA treatment on K562 cells. (A) PPIX detection for $1 \mathrm{mM}$ ALA concentration measured by FACS along the time. (B) ALA concentration-dependent curve of PPIX accumulation at $24 \mathrm{~h}$ after treatment measured by FACS. (C) Effect of PK 11195 upon ALA-induced PPIX accumulation at $24 \mathrm{~h}$ after treatment measured by FACS $(\mathbf{\square}, \Delta, \bullet$ and $\circ$ for $0.1,0.2,0.3$ and $0.4 \mathrm{mM}$ ALA, respectively). Effect of PK 11195 upon porphyrin intermediates accumulated in cells (D) or secreted from K562 cells (E) upon 0.4 mM ALA treatment compared to cells without PK 11195 treatment (NT) (black, white and grey bars correspond to PPIX, coproporphyrin - copro and uroporphyrin - uro, respectively). (F) Western blot of TSPO2 in K562 and UT-7 whole cell lysates.

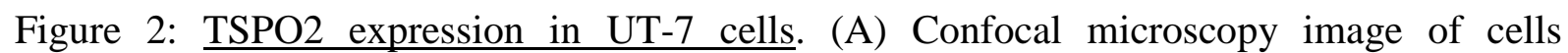
immunolabelled with anti-TSPO2 (green) and Hoechst day, nuclear markers (blue) (scale bar,

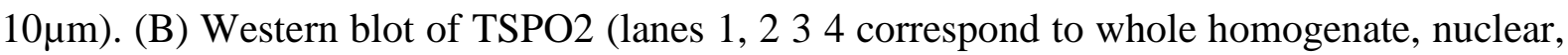
mitochondrial and plasma membrane fractions, respectively) and GPA, plasma membrane marker. The strong band around $25-35 \mathrm{kDa}$ observed in the membrane fraction do not correspond to hTSPO2 since it is revealed by pre-immune serum.

Figure 3: ALA-induced PPIX accumulation in UT-7 cells. (A) Concentration dependence after $24 \mathrm{~h}$ treatment measured by FACS. (B) Concentration-dependent inhibition of ALAinduced PPIX accumulation by PK 11195 after $24 \mathrm{~h}$ treatment measured by FACS ( $\square$ and for 0.3 and $0.5 \mathrm{mM}$ ALA, respectively). (C) Kapp for PK 11195 inhibition of PPIX accumulation as a function of ALA concentration. Results presented as the means \pm standard error of the mean (SEM). Inhibitory effect of PK 11195 upon porphyrin intermediates 
accumulated in UT-7 cells (D) and secreted in the culture medium of UT-7 cells (E) after treatment with $0.3 \mathrm{mM}$ ALA (black, grey and white bars correspond to PPIX, uroporphyrin uro and coproporphyrin - copro, respectively) (NT - cells non-treated by PK 11195).

Figure 4: Effect of PK 11195 upon enzyme activity. (A) ALA deshydratase (ALAD) and (B) ferrochelatase enzymatic activity measured by the formation of zinc-mesoporphyrin by insertion of zinc into mesoporphyrin (NT - cells non-treated by PK 11195).

Figure 5: PBG-induced PPIX accumulation in UT-7 cells. (A) Concentration dependence after $24 \mathrm{~h}$ treatment measured by FACS. (B) Effect of PK 11195 upon PBG-induced PPIX accumulation after $24 \mathrm{~h}$ treatment measured by FACS (0.4 mM PBG). Effect of PK 11195 upon porphyrin intermediates accumulated in UT-7 cells (C) and secreted in the culture medium of UT-7 cells (D) upon $0.4 \mathrm{mM}$ PBG induction (black and gray bars correspond to PPIX and uroporphyrin, respectively).

Figure 6: Effect of classical competitors of ALA. (A) ALA-induced PPIX accumulation after $24 \mathrm{~h}$ treatment measured by FACS with or whithout PK $11195(60 \mu \mathrm{M})$, GABA $(0.2 \mathrm{mM}), \mathrm{L}-$ leucine $(0.2 \mathrm{mM})$, L-citruline $(0.2 \mathrm{mM})$ and non-treated cells $(\mathrm{NT})$. (B) Free PPIX and ZnPPIX accumulated in UT-7 cells after $24 \mathrm{~h}$ treatment with $0.3 \mathrm{mM}$ ALA in the presence of increasing PK 11195 concentrations.

Figure 7: $\underline{\text { Overexpression of TSPO } 2 \text { increased ALA- induced PPIX accumulation in K562 }}$ cells. (A) Transfection efficiency $20 \mathrm{~h}$ post-transfection. (B) Quantification of TSPO2 mRNA by qPCR from cell cultures showing 55 to $60 \%$ of GFP positive cells $20 \mathrm{~h}$ after transfection $(n=3)$. On the top is mentioned the median of fluorescence of GFP positive cells, reflecting 
the number of vector copies per cell. (C) Representative Western blotting profile of transfected and non-transfected cells lysates hybridized with either an anti-TSPO2, an antiGFP or the rabbit pre-immune serum. (D) TSPO2-GFP localization 16 and $20 \mathrm{~h}$ (i.e., $1 \mathrm{mM}$ ALA for $4 \mathrm{~h}$ ) after transfection. Mitochondria are stained using mitotracker deep red. (E) Overlay of representative cytometry profiles of transfected (GFP positive) and nontransfected (GFP negative) cells from the same culture incubated four $\mathrm{h}$ with $1 \mathrm{mM}$ ALA $16 \mathrm{~h}$ post-transfection. In gray, PPIX negative population. (F) Percentage of cells accumulating PPIX after four hours of ALA treatment added 16 hours post-transfection in transfected (GFP positive) and non-transfected (GFP negative) cells. (G) PPIX median of fluorescence of cells positive for PPIX accumulation after four hours of ALA treatment in transfected (GFP positive) and non-transfected (GFP negative) cells.

Figure 8: Scheme of ALA-mediated porphyrin synthesis in cells. In the cytosol, the cyclic tetrapyrrole, coproporphyrinogen III, is formed from ALA in a series of four enzymatic reactions. Coproporphyrinogen III is then transported into the mitochondrial intermembrane space by putative mitochondrial importer ABCB6. Krishnamurthy et al., 2006 reported that inhibition of ABCB6 abolished mitochondrial porphyrin uptake. ABCB6 binds to various porphyrins, including coproporphyrinogen III, PPIX, and heme. Because it exhibits the highest affinity to coproporphyrinogen III, ABCB6 is believed to be involved in transporting coproporphyrinogen III into mitochondria. Coproporphyrinogen III is then converted into protoporphyrinogen III that is transported into the matrix by a mechanism requiring TMEM14C (Yien at al., 2014). Heme is formed from PPIX by the action of ferrochelatase. ABCG2 was described as involved in PPIX across the mitochondrial and plasma membrane to maintain intracellular porphyrin homeostasis (Kobuchi et al., 2012). The knockdown of ABCG2 causes PPIX accumulation, particularly in mitochondria, and results in mitochondrial 
damage, indicating that PPIX is an endogenous substrate of ABCG2 (Lin et al., 2013). Heme is thought to be exported by FLVCR1b into the cytosol (Chiabrando et al., 2012) and by FLVCR1a outside the cells (Keel et al., 2008). Abbreviations used: ALA: 5-aminolevulinic acid, ALAS: ALA synthase; ALAD: ALA dehydratase, ABCB6: ATP binding casette transporter B6, ABCG2: ATP binding casette transporter G2, PBG: porphobilinogen, COPRO: coproporphyrin, CPOX: coproporphyrinogen oxidase, FECH: ferrochelatase, FLVCR1a and 1b: feline leukemia virus subgroup $\mathrm{C}$ receptor $1 \mathrm{a}$ and 1b, HMBS: hydroxymethylbilane synthase, PEPT1/2: oligopeptide transporter, PPOX: protoporphyrinogen oxidase, TMEM14C: Transmembrane protein 14C, TSPO2: Translocator protein 2 18kDa, URO: uroporphyrin, UROS: uroporphyrinogen synthase, UROD: uroporphyrinogen decarboxylase.

\section{Supplementary Figure Legend}

Supplementary Figure S1: Heme biosynthesis pathway. Abbreviations: ALAS: ALA synthase; ALAD: ALA dehydratase; HMBS: hydroxymethylbilane synthase; UROS: uroporphyrinogen synthase; UROD: uroporphyrinogen decarboxylase; CPOX: coproporphyrinogen oxidase; PPOX: protoporphyrinogen oxidase; FECH: ferrochelatase. 